\title{
Properties of corn starch subjected hydrothermal modification**
}

\author{
Artur Gryszkin*, Tomasz Zięba, and Małgorzata Kapelko-Żeberska \\ Department of Food Storage and Technology, Wroclaw University of Environmental and Life Science, \\ Chełmońskiego 37, 51-630 Wrocław, Poland
}

Received June 1, 2016; accepted December 14, 2016

\begin{abstract}
A b s t r a c t. The objective of this study was to determine the effect of heating a water dispersion of corn starch to various temperatures, followed by its freezing and defrosting, on selected properties of re-formed starch pastes. A suspension of starch was heated to various temperatures ranging from 59 to $94^{\circ} \mathrm{C}$, and afterwards frozen and defrosted. The differential scanning calorimetry (Mettler Toledo, 822E) thermal characteristics of starch pre-heated to temperatures not inducing complete pasting revealed transitions of: (I) retrograded amylopectin, (II) non-pasted starch, (III) amylose-lipid complexes, (IV) retrograded amylose, and (V) highly thermostable starch structures. The application of higher temperatures during heating caused disappearance of transitions II and V. The increase of pre-heating temperature induced firstly a decrease and then stabilization of the swelling power as well as a successive decrease in starch solubility. Pastes pre-heated to temperatures over $79^{\circ} \mathrm{C}$ contained large macroparticles that were increasing viscosity of the re-formed starch paste (their size was positively correlated with viscosity value).

K e y w o r d s: corn starch, hydrothermal treatment, freezing, thermal characteristics of pasting, rheology, size of swollen granules
\end{abstract}

\section{INTRODUCTION}

In 2009, the global production of starch reached $c a$. $68 \mathrm{mln}$ tones (Patil, 2010). By the year 2018, it is estimated to double to the value of $133.5 \mathrm{mln}$ tones (Global Industry Analyst, 2015). So dynamic development of the starch industry is linked with the multi-functional utility of starch and its modified preparations. Starch is applied in the food and many other industries, like: pharmaceutical, textile, chemical and building industries. Such a wide applicability of starch is feasible by imparting it new traits on the

*Corresponding author e-mail: artur.gryszkin@upwr.edu.pl **This work was supported by the Wrocław Centre of Biotechnology program 'The Leading National Research Centre (KNOW)' for years 2014-2018. route of enzymatic, physical and chemical modifications. Properties of starch are modified so as to correspond to a specified practical application.

Chemical modified starch products used in food industry as food additives have faced increasingly widespread objection among consumers. Therefore other methods changing the starch properties have been looked for. One of them is annealing which is hydrothermal starch hardening. This physical modification depends on starch heating in water at temperature between glass transition and initial gelatinization temperature of native starch, where amorphous transitions of glassy polymer systems are induced into more plastic state (Tester and Debon, 2000). As a result of this process the starch chains are ordered and stiffened caused the increasing of starch crystallinity degree (Leszczyński, 2004). Moreover during the heating comes to physical reorganization of starch molecules, without causing their destruction, but only changing their properties, which depend on the botanical origin of starch, temperature and its uptime as well as on starch concentration in water (Zavareze and Dias, 2011).

Previous research concerning potato starch and wheat starch modified physically by heating starch suspension, followed by its freezing and defrosting, demonstrated a significant increase in the viscosity of re-formed pastes that was correlated with the size of macroparticles formed during hydrothermal modification (Gryszkin et al., 2014; $2016 \mathrm{a} ; 2016 \mathrm{~b})$. In the case of potato starch, the greatest changes in viscosity occurred when the starch suspension was heated to the temperature of $74^{\circ} \mathrm{C}$ before freezing. In the case of wheat starch, the respective temperature was significantly higher and reached $94^{\circ} \mathrm{C}$. These differences, resulting presumably from biodiversity of starch, inspired

(C) 2017 Institute of Agrophysics, Polish Academy of Sciences 
us to conduct an analogous experiment with corn starch which has the greatest contribution in the global starch market (http://www.starch.dk/ISI/stat/rawmaterial.asp).

This study was aimed at determining the effect of heating a water dispersion of corn starch to various temperatures, followed by its freezing and defrosting, on its selected properties as well as on properties of the prepared starch pastes.

\section{MATERIALS AND METHODS}

The initial experimental material was $\mathrm{C}^{*} \mathrm{Gel} 03401$ corn starch produced in 2012 by Cargill Deutschland $\mathrm{GmbH}$ company in Krefeld.

Native corn starch was used to prepare $450 \mathrm{ml}$ of an

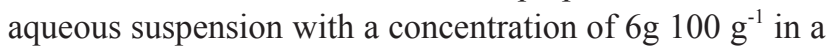
measuring vessel of Brabender viscograph (Germany). The suspension was heated under continuous stirring and at the rate of $1.5^{\circ} \mathrm{C} \mathrm{min}^{-1}$ to the following temperatures: $59,61.5$, $64,66.5,69,71.5,74,76.5,79,81.5,84,86.5,89,91.5$ or $94^{\circ} \mathrm{C}$. The resultant solution was cooled to $30^{\circ} \mathrm{C}$ with the rate of $1.5^{\circ} \mathrm{C} \mathrm{min}^{-1}$ and then frozen in a freezer (Bosch, Poland) for two days at a temperature of $-20^{\circ} \mathrm{C}$. Afterwards, it was defrosted for two hours in a water bath (Memmert, Germany) at a temperature of $40^{\circ} \mathrm{C}$. The native starch (not subjected to hydrothermal modification) was assigned the symbol CNS, whereas starches subjected to pre-heating were assigned the following symbols: C59, C61.5, C64, C66.5, C69, C71.5, C74, C76.5, C79, C81.5, C84, C86.5, $\mathrm{C} 89, \mathrm{C} 91.5$ or $\mathrm{C} 94$ (the number after letter ' $\mathrm{C}$ ' denotes temperature which the starch suspension was heated to before thawing). The water absorption and water solubility, particle size, characteristic of re-creation the pastes were determined directly after thawing the suspension. The Differential Scanning Calorimetry (DSC) (Mettler Toledo, 822E) characteristic (due to the small starch concentration) was determined after drying the starch.

Thermal characteristics was determined according to the method by Gryszkin et al. (2014). The modified preparations were dried in an air dryer (Memmert, Germany) at a temperature of $30^{\circ} \mathrm{C}$ for $24 \mathrm{~h}$, ground and sieved through a screen with mesh size of $400 \mu \mathrm{m}$. Determination was carried out with the use of an $822 \mathrm{E}$ differential scanning calorimeter DSC (Mettler Toledo, Germany). Before the measurement, the calorimeter was calibrated using a sample of indium and a sample of zinc. The analyzed sample (ca. $10 \mathrm{mg}$ on dry matter basis) was placed on the bottom of a vessel (MEDIUM PRESSURE ME-29990), and then distilled water was added in the ratio of 3:1 (water:starch). The vessel was closed and thus prepared sample was conditioned for $30 \mathrm{~min}$ at $25^{\circ} \mathrm{C}$. The analysis was conducted in a temperature range from 25 to $200^{\circ} \mathrm{C}$, at the heating rate of $10^{\circ} \mathrm{C} \mathrm{min}{ }^{-1}$. The thermal characteristics of pasting served to determine the heat of transition as well as initial and final temperatures of pasting, using StarSoftware (Mettler Toledo, Germany).

The swelling power and solubility in water of the produced preparations were determined according to the method by Kapelko et al. (2012). The defrosted solution of starch was used to prepare an aqueous suspension with the concentration of $1 \mathrm{~g}$ starch per $100 \mathrm{~g}$ solution. Next, the suspension was shaken in a water bath at $80^{\circ} \mathrm{C}$ for $30 \mathrm{~min}$. Afterwards, the sample was cooled to a temperature of $20^{\circ} \mathrm{C}$ and centrifuged for $30 \mathrm{~min}$ in a Biofuge 28RS Heraeus Sepatechc centrifuge with acceleration of $22.500 \times \mathrm{g}$. The separated supernatant was determined for dry matter content with the gravimetric method, whereas the precipitate left in the centrifuge tubes was weighed.

The size of solid particles present in the pastes prepared from starch heated to various temperatures and then frozen and defrosted was determined according to the method by Gryszkin et al. (2014). After freezing and defrosting, a starch suspension was transferred into a measuring vessel of a Brabender viscograph (Germany) with a $700 \mathrm{cmg}$ measuring can. The suspension was kept at $40^{\circ} \mathrm{C}$ for $10 \mathrm{~min}$ under continuous stirring at the speed of $75 \mathrm{rpm}$. Afterwards, it was heated to a temperature of $94^{\circ} \mathrm{C}$ with the rate $1.5^{\circ} \mathrm{C}$ $\min ^{-1}$ and kept at this temperature for $10 \mathrm{~min}$. Particle size was determined using a Mastersizer 2000 particle size laser analyzer (Malvern Instruments LTD, England) with a Hydro 2000 MU unit. Particle size in the paste, expressed by the mean volumetric diameter $\mathrm{D}[4,3]$, was determined once the paste had reached the temperature of $94^{\circ} \mathrm{C}(\mathrm{D}$ 94) and after keeping the paste at the temperature of $94^{\circ} \mathrm{C}$ for $10 \mathrm{~min}$ (D 94/10). Measurements were carried out at the obscurance of $\sim 20 \%$. In order to disintegrate starch agglomerates, the analyzed solution was treated for $15 \mathrm{~s}$ with ultrasounds $(20 \mathrm{~Hz})$ before each measurement.

The re-pasting characteristics was determined analogously to particle size determination. A measuring vessel of Brabender viscograph (Germany) with a defrosted solution was placed in the apparatus and kept at a temperature of $40^{\circ} \mathrm{C}$ for $10 \mathrm{~min}$, under continuous stirring with the speed of 75 r.p.m. Afterwards, the sample was heated to a temperature of $94^{\circ} \mathrm{C}$ with the rate of $1.5^{\circ} \mathrm{C} \mathrm{min}^{-1}$. After keeping the mixture at this temperature for $10 \mathrm{~min}$, it was cooled to $30^{\circ} \mathrm{C}$ with the rate of $1.5^{\circ} \mathrm{C} \mathrm{min}^{-1}$ and kept at this temperature for $10 \mathrm{~min}$. The pasting characteristics allowed determining viscosity of the paste once it had reached a temperature of $94^{\circ} \mathrm{C}(\eta 94)$ and viscosity of the paste kept at $94^{\circ} \mathrm{C}$ for $10 \min (\eta 94 / 10)$.

Results obtained were subjected to statistical analyses with the use of Statistica 12 software package (StatSoft, USA). Values of the least significant differences (Duncan LSD test) were established based on statistical calculations - one-way analysis of variance at a significance level of 0.05 (from at least three parallel replications). 
Experimental data were also used to determine correlations between selected traits that were described with second degree polynomial equations. Simple correlations were also determined between paste viscosity and particle size as well as between solubility of the modified preparations and pre-heating temperature of a starch dispersion. Afterwards, Student t-test was used to determine the significance of Pearson simple correlation coefficient.

\section{RESULTS AND DISCUSSION}

Differential scanning calorimetry (DSC) is based on the measurement of heat fluxes flowing to the experimental and control samples during heating (or cooling). The difference in the quantity of heat supplied to the experimental sample compared to the control sample indicates thermal transition ongoing in the examined material. According to method assumptions, in order to minimize errors resulting from $e g$ the inertia or heat conductivity of the sample, the analysis is carried out in the microscale ie on microgram quantities of the sample. If the analyzed materials are homogenous, the signal is usually large enough and hence easy to be identified and interpreted. The analyzed corn starch that had been heated in water, then frozen and defrosted was a very heterogeneous sample in which different starch structures dissolved at various temperatures often with a low heat of transition.

Table 1 presents parameters (peak temperature and heat of transition) of 5 transitions visible on the obtained thermograms. Transition I corresponds to dissolution of retrograded amylopectin (Silverio et al., 2000), whereas transition II - gelatinization of native starch ( $\mathrm{Li}$ et al., 2007). Native starch gelatinization transition occurred only in the samples heated before freezing to lower temperatures $\left(59-69^{\circ} \mathrm{C}\right)$ that were insufficient for complete gelatinization of starch. Heat of this transition was decreasing along with an increasing temperature of pre-heating and, consequently, along with a decreasing amount of non-pasted native starch present in the analyzed sample. In the discussed range of pre-heating temperatures, an opposite tendency occurred in the case of transition of retrograded amylopectin dissolution. Heat of this transition was increasing to $c a .5 \mathrm{~J} \mathrm{~g}^{-1}$ owing to the increasing amount of this starch fraction that was formed during freezing from an increasing amount of pasted starch. The successive increase of pre-heating temperature did cause any significant changes in the heat of this transition.

Transition III corresponds to dissolution of the amylose-lipid complex occurring naturally in cereal starches (Nebesny et al., 2005). This transition occurred in all analyzed samples, because the pre-heating did not cause dissolution of the complexes. The first three transitions visible in thermograms of native or retrograded corn starch were described in many research publications (Krueger et al., 1987; Yoshimura et al., 1996; Xu et al., 2012; Zhong and Sun, 2005). The thermal characteristics of corn starches heated in a water suspension to various temperatures and then frozen and defrosted revealed the presence of transitions IV and V. Transition IV occurred in all DSCs, with peak temperature ranging from 129.4 to $153.3^{\circ} \mathrm{C}$ and heat of transition ranging from 0.1 to $1.3 \mathrm{~J} \mathrm{~g}^{-1}$. Based on literature data, it may be concluded explicitly that it was transition of retrograded amylose dissolution. Yu et al., who investigated the process of retrogradation of pure amylose isolated from starch, demonstrated that peak temperature ranged from 119 to $127^{\circ} \mathrm{C}$ and depended on starch origin and retrogradation conditions (Yu et al., 2014). In turn, when describing the mechanism of RS 3 resistant starch (retrograded starch) formation, Leszczyński stated that retrogradation of amylose resulted in the formation of thermostable structures soluble at a temperature of $c a .150^{\circ} \mathrm{C}$, as dependent on the origin of starch, length of amylose chain and conditions of retrogradation (Leszczyński, 2004).

Especially interesting from the perspective of investigations on starch is the presence of so far non-reported transition $\mathrm{V}$ on thermograms. It is common knowledge that the process of annealing itself changes the crystalline structure of starch (Jayakody and Hoover, 2008). The heating of potato starch in water at a temperature lower than the gelatinization temperature causes elongation of double helices (Genkina et al., 2003). The annealing of corn starch causes the formation of new double helixes with amylose participation (Tester et al., 2000), whereas its heating in water make mixing the crystalline and amorphous structures ( $\mathrm{Zu}$ et al., 2016). The annealing leads to interactions between starch components, thus causing an increase in the stability of starch granules (Hoover and Vasanthan, 1994). Liu et al. (2006) as well as Maache-Rezzoug et al. (2008) described the possibility of the occurrence of transition at a temperature of $c a .180^{\circ} \mathrm{C}$ in the thermal characteristics of corn starch. This transition, however, occurs only at a low moisture content of the sample and is interpreted not as pasting but as melting of starch structures. Similar changes were reported by Yu and Christie (2001), who additionally observed that the presence of the described transition in the thermogram was affected not only by the moisture content of starch but also by the size of the weighted portion or type of vessels used for analyses. In the conducted study, the coupling of annealing (starch heating in water in a temperature range from 61.5 to $69^{\circ} \mathrm{C}$ ) as well as freezing and defrosting could induce the formation of highly thermostable starch structures. Detailed explanation of the mechanism of formation and determination of the structure of formed starch fraction would, however, require additional investigations.

Hydrothermal treatment of corn starch induced changes in its swelling power and solubility in water. The increase of the pre-heating temperature in the range of $59.0-71.5^{\circ} \mathrm{C}$ caused a decrease in the swelling power from 18.5 to $12.6 \mathrm{~g} \mathrm{~g}^{-1}$ (Fig. 1). Further increase of temperature did not 


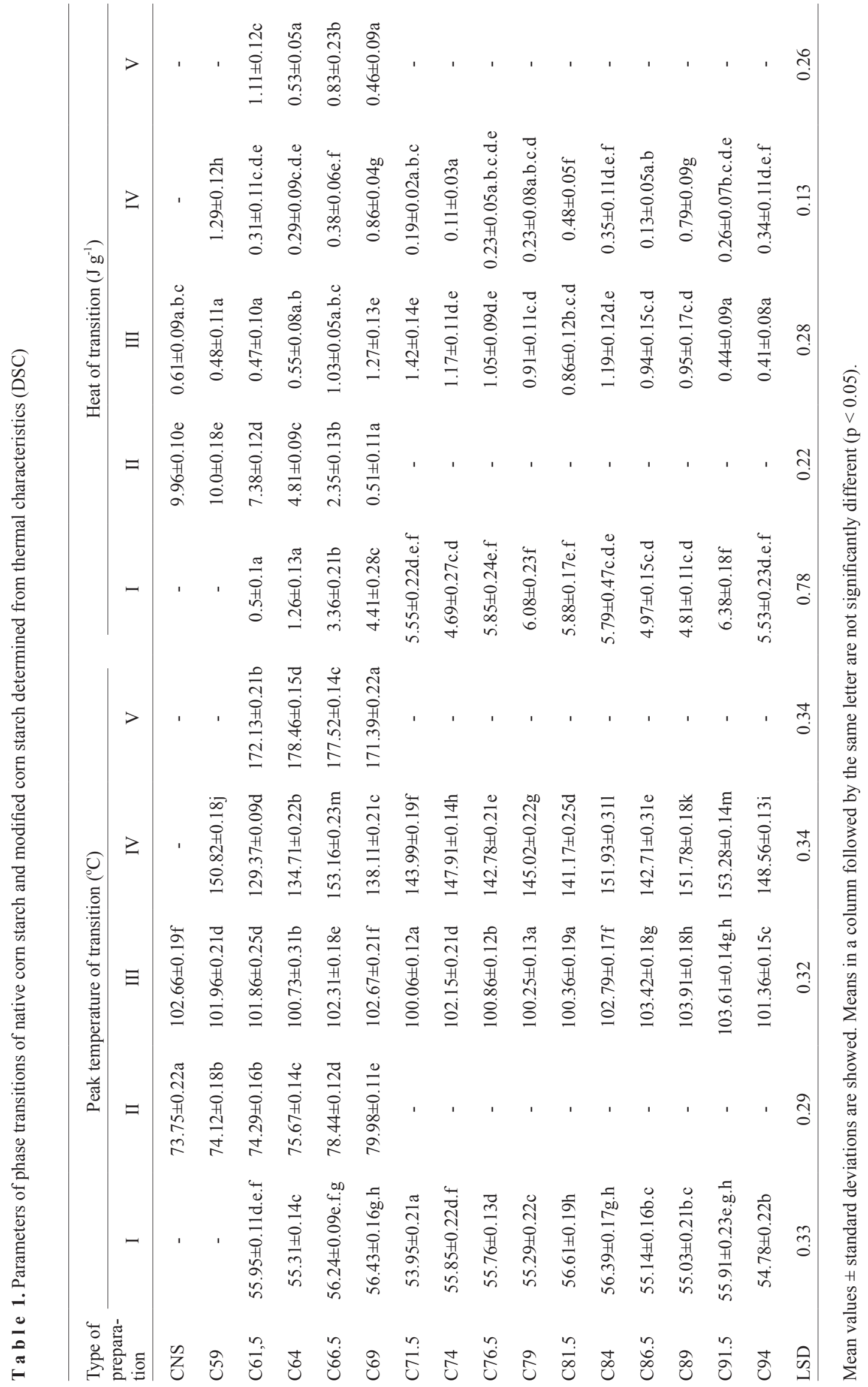




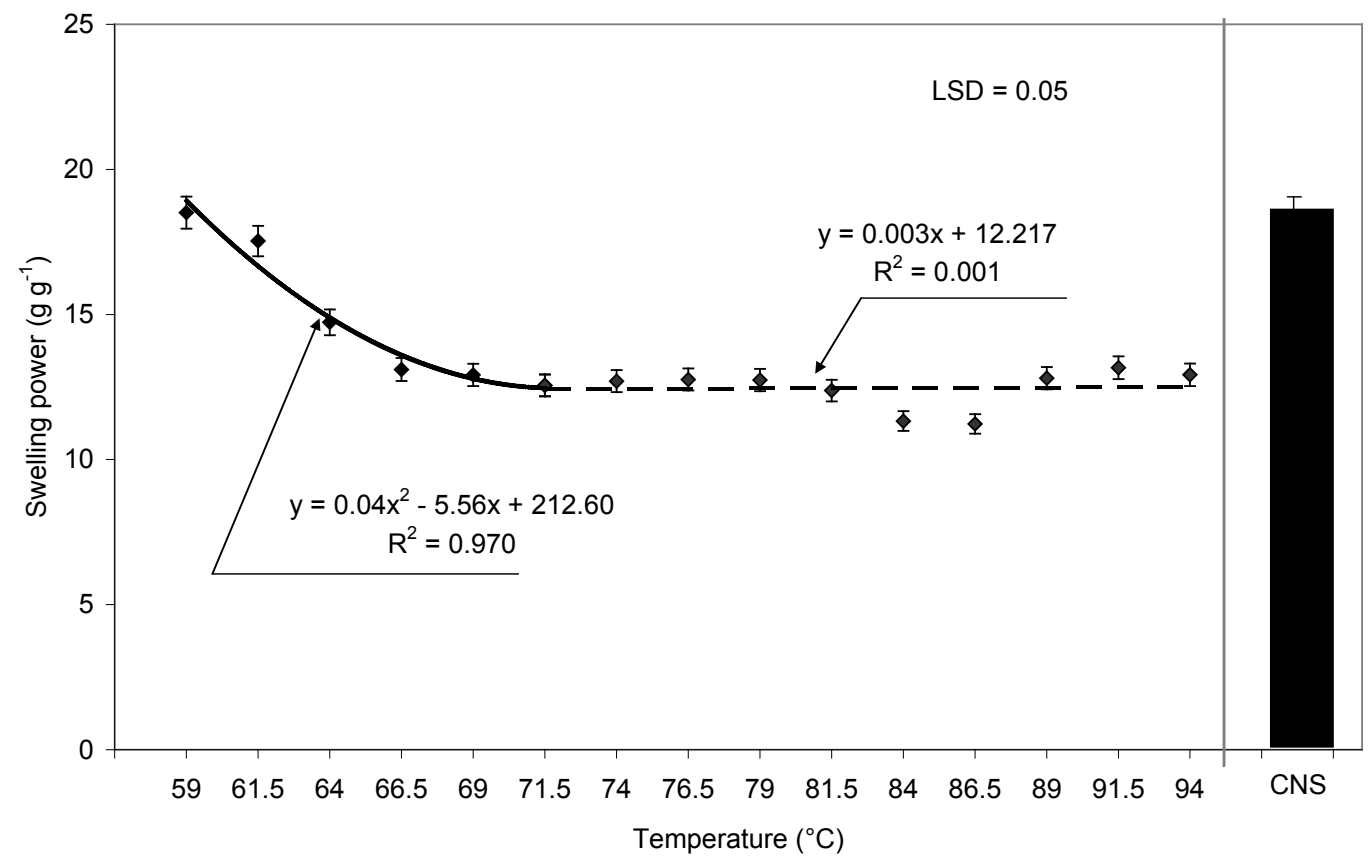

Fig. 1. Swelling power of native starch (CNS) and dependency of swelling power on temperature of starch dispersion heating before freezing.

cause any significant changes in the values of this trait. It may, therefore, be concluded that in the conducted experiment the key factor that affected the swelling power was not temperature but the degree of starch pasting before freezing. Starch heated before freezing to a temperature of $59^{\circ} \mathrm{C}$ was characterized by the same swelling power as native starch, whereas that heated to temperatures causing complete pasting - was characterized by lower swelling power maintaining at a similar level. As reported by Tester and Morisson (1990), the swelling power of starch is determined, to a significant extent, by the content and properties of amylopectin. It is common knowledge that during the pasting process, first amylose and starch fractions with a lower molecular weight migrate into the solution. Amylopectin 'pours out' to the solution at latest, during the breaking of gel sacks (swollen starch globules). In the present study, the swelling power was, presumably, affected by the degree of amylopectin unwinding in a colloidal solution, which influenced the retrogradation process ongoing during freezing. It may, therefore, be speculated that the differences in the swelling power of starch are due to changes proceeding in amylopectin as a result of this process. Starch heated before freezing to a temperature of $59^{\circ} \mathrm{C}$ was characterized (as in the case of swelling power) by a similar solubility to that of the native starch. Heating to higher temperatures reduced starch solubility in water, with the decrease being greater the lower was the temperature of pre-heating. The solubility of starch is determined by the content of lower-molecular starch substances (mainly amylose) which under specified conditions migrate into the solution. As indicated by DSC analysis conducted in the present study, starch retrogradation did occur during freezing. By forming thermostable structures under assay conditions (temperature of $80^{\circ} \mathrm{C}$ ), amylose did not migrate to the solution, which resulted in lower solubility of starch. Based on a strong (0.97) negative correlation between solubility and pre-heating temperature (Fig. 2), it may be concluded that the increasing temperature of pre-heating was accompanied by an increasing number of the formed thermostable starch structures.

Correlations between the size of solid particles formed in the pastes prepared from starch heated to various temperatures and the frozen and thawed is presented in Fig. 3. The mean volumetric diameter $\mathrm{D}[4 / 3]$ of the particles present in the pastes prepared from native starch (non-modified) and heated before freezing to temperatures ranging from 59 to $79^{\circ} \mathrm{C}$ reached $c a .45 \mu \mathrm{m}$. Once the temperature of $79^{\circ} \mathrm{C}$ is exceeded, the size of the particles increases, with the increase being higher along with the higher temperature of pre-heating. The diameter of the particles present in the paste prepared from starch heated before freezing to $94^{\circ} \mathrm{C}$ was $c a .8$ times greater than the diameter of the particles in the paste made of native starch. Thus, it may be undoubtedly concluded that the increase of temperature facilitates the formation of large thermostable macroparticles of starch. In the analogous study with wheat starch, changes in the particle size were similar (Gryszkin et al., 2016a), but in the case of potato starch - they were significantly lesser and not correlated with the increasing temperature of preheating (Gryszkin et al., 2014). 


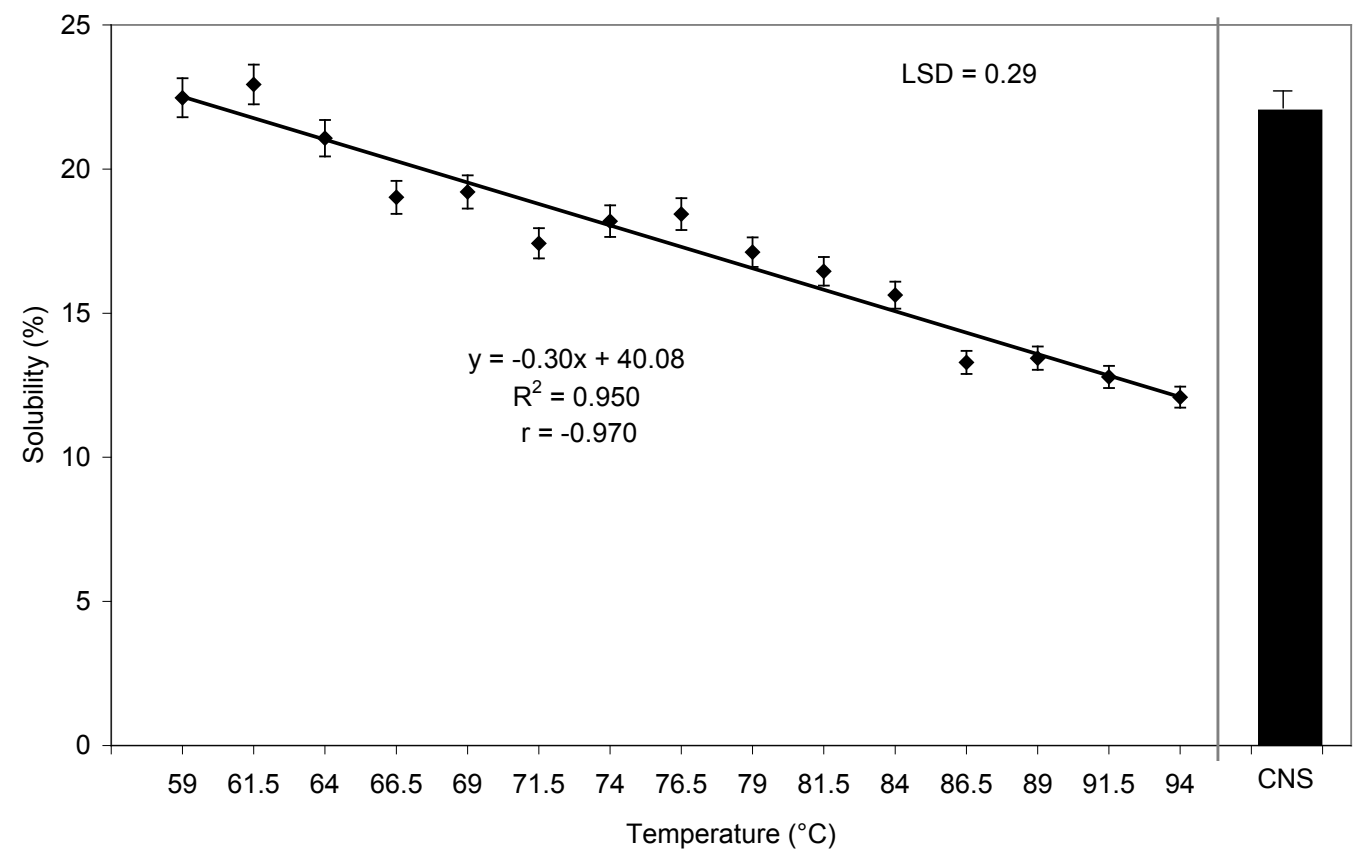

Fig. 2. Solubility of native starch (CNS) in water and dependency of starch solubility in water on temperature of starch dispersion heating before freezing.

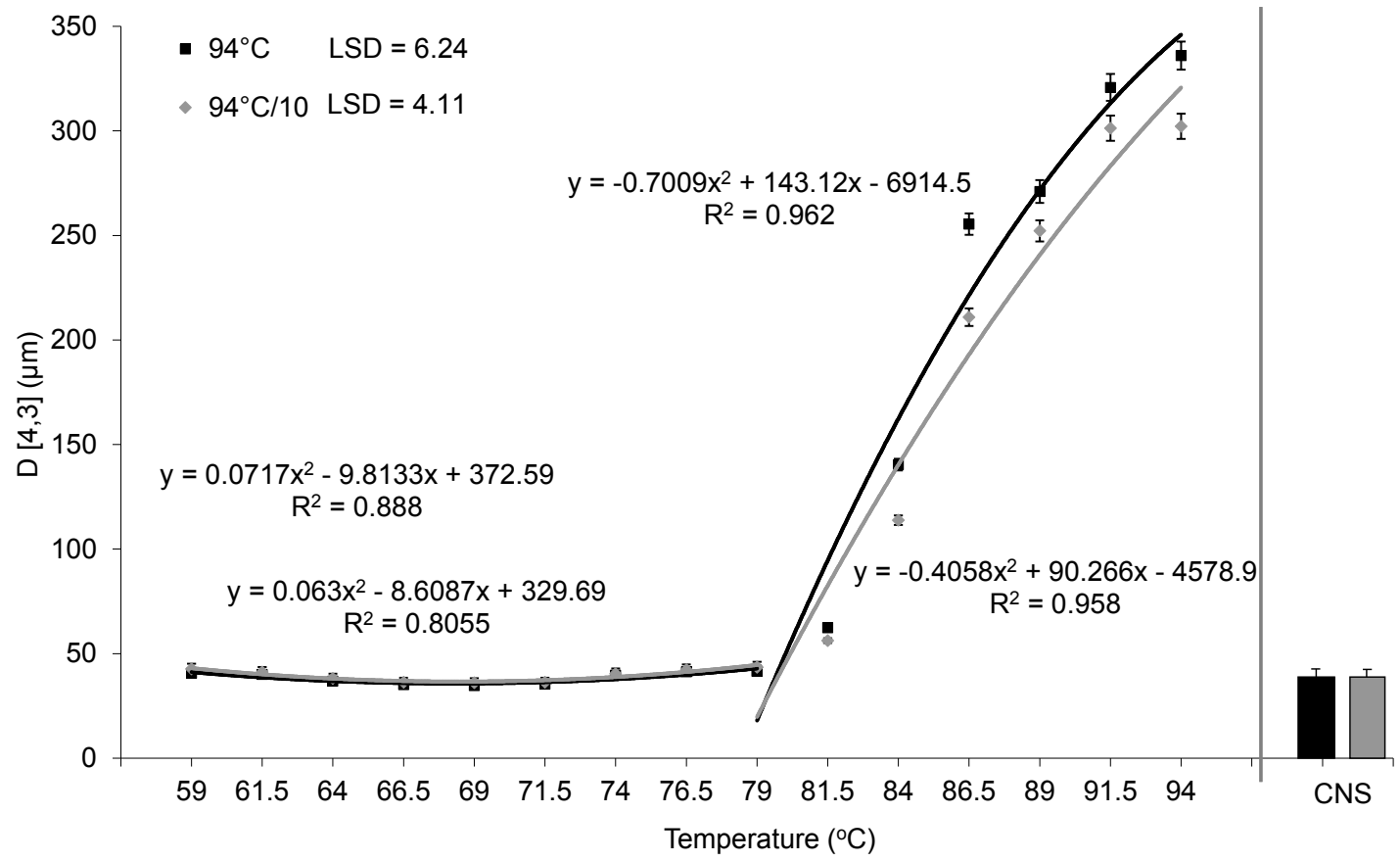

Fig. 3. Particle size in paste made of native starch (CNS) and dependency of paste particle size on temperature of starch dispersion heating before freezing, determined at $94^{\circ} \mathrm{C}$.

The formation of large macroparticles of corn starch during heating, freezing and thawing had a significant effect upon the viscosity of formed pastes (Fig. 4). The heating of a starch suspension to temperatures ranging from 59 to $79^{\circ} \mathrm{C}$ caused no changes in paste viscosity. As in the case of particle size determination, exceeding this temperature caused a rapid increase in paste viscosity. The paste prepared from starch heated before freezing to the temperature of $94^{\circ} \mathrm{C}$ was characterized by about twofold higher viscosity compared to the paste made of native starch. The large thermostable starch structures, formed during hydrothermal modification and confirmed with the DSC analysis, did not dissolve during paste formation, and it was their presence that was the cause of increasing paste viscosity. 


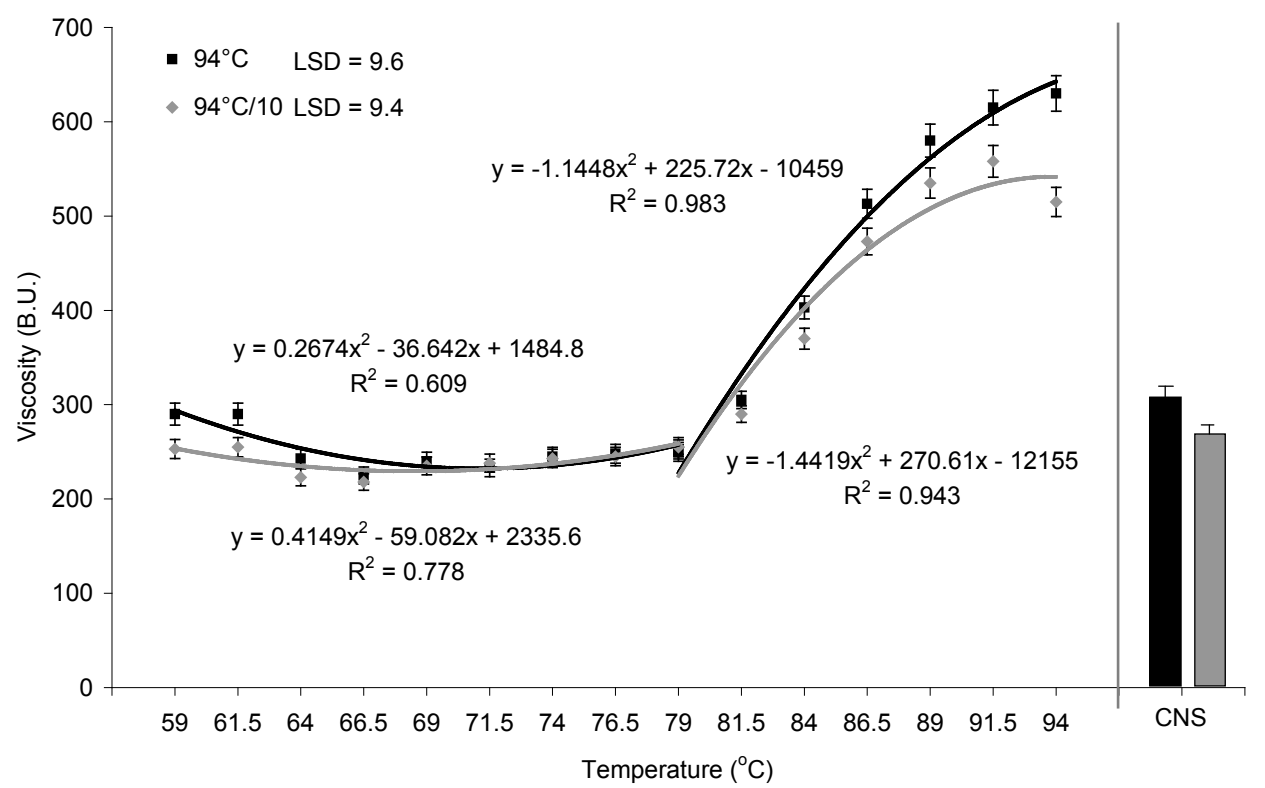

Fig. 4. Viscosity of native starch (CNS) and dependency of paste viscosity on temperature of starch dispersion heating before freezing, determined at $94^{\circ} \mathrm{C}$.

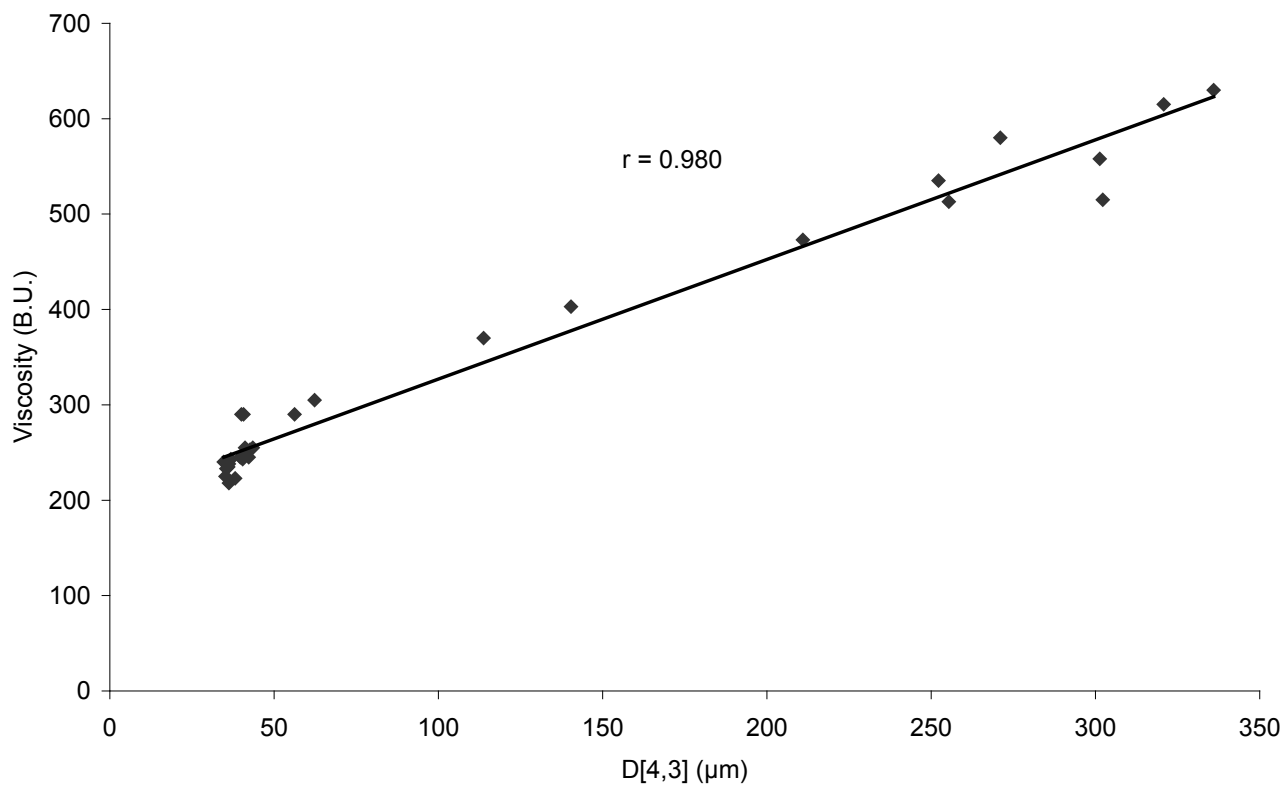

Fig. 5. Dependency of paste viscosity on particle size in the modified starch preparation, determined at $94^{\circ} \mathrm{C}$.

This is additionally confirmed by a strong correlation $(\mathrm{r}=0.980)$ determined between particle size and paste viscosity (Fig. 5). Similar correlations were shown in analogous experiments with wheat starch (Gryszkin et al., 2016a) and potato starch (Gryszkin et al., 2014).

\section{CONCLUSIONS}

1. The heating of a corn starch suspension, followed by its freezing and defrosting, induced changes in its properties, with the tendencies and extent of these changes being dependent on the temperature of pre-heating.
2. The increase of pre-heating temperature caused firstly a decrease and then stabilization of the swelling power as well as a successive decrease of starch solubility.

3. Starch heating to temperatures over $79^{\circ} \mathrm{C}$ facilitated the formation of its thermostable macroparticles which, in turn, were contributing to the increasing viscosity of the re-formed starch paste, and the size of these macroparticles was positively correlated with paste viscosity.

4. The paste prepared from starch heated before freezing to the temperature of $94^{\circ} \mathrm{C}$ was characterized by about twofold higher viscosity compared to the paste made of native starch. 
Conflict of interest: The Authors do not declare conflict of interest.

\section{REFERENCES}

Genkina N.K., Wasserman L.A., and Yuryev V.P., 2003. Effect of short- and long-time annealing on structure and properties of starches from potato tubers grown at different environmental temperatures. 11th Int. Starch Convention, June 17-19, Moscow, Russia.

Global Industry Analysts INC, 2015. Starch: A Global Strategic Business Report. (Chapter - Highlights).

Gryszkin A., Zięba T., Kapelko M., and Buczek A., 2014. Effect of thermal modifications of potato starch on its selected properties. Food Hydrocolloid., 40, 122-127.

Gryszkin A., Zięba T., Kapelko-Żeberska M., and Atraszkiewicz A., 2016a. Hydrothermal modification of wheat starch. Part 1. Effect of particle size on the viscosity of formed pastes. J. Cereal Sci., 68, 46-52.

Gryszkin A., Zięba T., and Kapelko-Żeberska M., 2016b. Hydrothermal modification of wheat starch. Part 2. Thermal characteristics of pasting and rheological properties of pastes. J. Cereal Sci., 69, 194-198.

Hoover R. and Vasanthan T., 1994. The effect of annealing on the physicochemical properties of wheat, oat, potato and lentil starches. J. Food Bochem., 17, 3003-325.

Jayakody L. and Hoover R., 2008. Effect of annealing on the molecular structure and physicochemical properties of starches from different botanical origins - A review. Carbohyd. Polym., 74, 691-703.

Kapelko M., Zięba T., Golachowski A., and Gryszkin A., 2012. Effect of the production method on the properties of RS3/ RS4 type resistant starch. Part 1: Properties of retrograded starch (RS3) produced under various conditions and its susceptibility to acetylation. Food Chem., 135/3,1494-1504.

Krueger B.R., Knutson C.A., Inglett G.E., and Walker C.E., 1987. A differential scanning calorimetry study on the effect of annealing on gelatinization behavior of corn starch. J. Food Sci., 52(3), 715-718.

Leszczyński W., 2004. Resistant Starch - classification, structure, production. Polish J. Food Nutri Sci., 13/34, SI I, 37-50.

Li J., Yeh A., and Fan K., 2007. Gelation characteristics and morphology of corn starch/soy protein concentrate composites during heating. J. Food Eng., 78, 1240-1247.

Liu H., Yu L., Xie F., and Chen L., 2006. Gelatinization of cornstarch with different amylose/amylopectin content. Carbohyd. Polym., 65, 357-363.
Maache-Rezzoug Z., Zarguili I., Loisel C., Queveau D., and Buléon A., 2008. Structural modifications and thermal transitions of standard maize starch after DIC hydrothermal treatment. Carbohyd. Polym., 74, 802-812.

Nebesny E., Kwaśniewska-Karolak I., and Rosicka-Kaczmarek J., 2005. Dependence of thermodynamic characteristics of amylose-lipid complex dissociation on a variety of wheat. Starch/Stärke, 57, 378-383.

Patil S.K., 2010. Global Modified Starch Products \& Carbohydrates Functional Foods Derivatives \& Markets - A Strategic Review - Abstract. Global Bussiness Development, Münster, Germany.

Silverio J., Fredriksson H., Andersson R., Eliasson A., and Aman P., 2000. The effect of temperature cycling on the amylopectin retrogradation of starches with different amylopectin unit-chain length distribution. Carbohyd. Polym., 42, 175-184.

Tester R.F. and Debon S.J.J., 2000. Annealing of starch a review. Int. J. Biol. Macromol., 27, 1-12.

Tester R.F., Debon S.J., and Sommerville M.D., 2000. Annealing of maize starch. Carbohyd. Polym., 42, 287-299.

Tester R.F. and Morisson W.R., 1990. Swelling and gelatinization of cereal starches I. Effect of amylopectin, amylose and lipids. Cereal Chem., 67, 551-557.

Xu Z., Zhong F., Li Y., Ch F., Yokoyama W. H., and Xia W., 2012. Effect of polysaccharides on the gelatinization properties of cornstarch dispersions. J. Agr. Food Chem., 60(2), 658-664.

Yoshimura M., Takaya T., and Nishinari K., 1996. Effects of Konjac-Glucomannan on the gelatinization and retrogradation of corn starch as determined by rheology and differential scanning calorimetry. J. Agr. Food Chem., 44(10), 2970-2976.

Yu L. and Christie G., 2001. Measurement of starch thermal transitions using differential scanning calorimetry. Carbohyd. Polym., 46, 179-184.

Yu S., Xu J., Zhang Y., and Kopparapu N.K., 2014. Relationship between intrinsic viscosity, thermal, and retrogradation properties of amylose and amylopectin. Czech J. Food Sci., 32(5), 514-520.

Zavareze E.d.R. and Dias A.R.G., 2011. Impact of heat-moisture treatment and annealing in starches: A review. Carbohyd Polym., 83, 317-328.

Zhong Z. and Sun X.S., 2005. Thermal characterization and phase behavior of cornstarch studied by differential scanning calorimetry. J. Food Eng., 69, 453-459.

Zu Y., Zhang B., Chen L., Xie F., Li L., and Li X., 2016. Supramolecular evolutions of maize starch hydrothermally treated in excess water. Starch-Starke, 68, 365-373.

http://www.starch.dk/ISI/stat/rawmaterial.asp - 29.02.2016 